\title{
Different multidimensional chromatographic approaches applied to the study of wine malolactic fermentation
}

\author{
L. Fernandes ${ }^{a}$, A.M. Relva ${ }^{a}$, M.D.R. Gomes da Silva ${ }^{a}$, A.M. Costa Freitas ${ }^{\text {b,* }}$ \\ ${ }^{a}$ Departamento de Química, Centro de Química Fina e Biotecnologia-CQFB, Faculdade de Ciências e Tecnologia/Universidade \\ Nova de Lisboa, Quinta da Torre 2829-516 Caparica, Portugal \\ ${ }^{\mathrm{b}}$ Departamento de Fitotecnia, Instituto de Ciências Agrárias e Mediterrânicas-ICAM, Universidade de Évora, Apt. 94, \\ 7002-554 Évora, Portugal
}

Received 11 October 2002; received in revised form 7 March 2003; accepted 18 March 2003

\begin{abstract}
Different multidimensional chromatographic techniques were used to study wine aroma pattern changes during malolactic fermentation (MLF). Ethyl lactate enantiomeric ratios were determined using on-line multidimensional gas chromatography. The values found agree with a spontaneous MLF. Off-line multidimensional HPLC/GC was used to deconvolute and enrich the sample and ease enantioselective chromatography. Chiral compound enantiomeric ratio changes during MLF were monitored. Evaluation of enantiomeric ratio changes during MLF has never been studied. $(R, R),(S, S)$ and meso-butane-2,3diol and pentane-2,4-diol (reported in wines for the first time) were submitted to untrained sensory panel tests. All stereoisomers revealed different sensory notes; pentane-2,4-diol showed an aromatic impact.
\end{abstract}

(C) 2003 Elsevier Science B.V. All rights reserved.

Keywords: Enantiomer separation; Malolactic fermentation; Multidimensional techniques; Wine; Pentane-2,4-diol

\section{Introduction}

Multidimensional (MD) separation techniques are a result of combining two or more independent or nearly independent separation techniques [1]. For complex samples, multidimensional techniques can provide a remarkable improvement on physical separation of individual compounds [1]. In conventional MD when the second dimension is a chiral column, two aims are achieved: reduced peak crowding and chiral separation. Off-line multidimensional

\footnotetext{
*Corresponding author. Tel.: +351-266-760-800x4334; fax: +351-266-711-163.

E-mail address: afreitas@uevora.pt (A.M. Costa Freitas).
}

chromatographic techniques can be used to prepare the sample to a refined separation on a second separation media [2,3]. The application of multidimensional techniques to the analysis of the aroma compound changes during MLF brought about the possibility of analysing the minor compounds and the possibility of their enantiomeric analysis. In wine flavour, terpenes, for instance, represent just $1 \%$ of the extract and are known to significantly contribute to the bouquet $[4,5]$. To achieve complete chemical information on wine volatile compounds, in addition to compound identification, it is important to study the structural configuration and enantiomeric ratio. In fact, the enantiomers of a compound can differ considerably in their odour, quality, and threshold. In 
addition, determination of enantiomeric excess (ee) can be used in adulteration detection [6,7]. MLF, the second wine fermentation, is considered as having the main role of reducing wine acidity. Most of the papers that deal with wine aroma changes during MLF are directed to the aroma impact of different compounds $[8,9]$, or the study of bacterial influence [10]. Results are controversial and conclusions are somehow different [7]. No authors have directed their attention, so far, to the enantiomeric changes produced during this fermentation. In fact, little attention has been given to the impact of enantiomers on wine aroma [11]. The use of conventional liquid chromatography to the pre-separation of complex aroma extracts has already been described and used in different types of samples [2,12-15]. Its use as a pre-separation technique prior to $\mathrm{GC}$ analysis of volatile compounds has not really been examined.

Off-line multidimensional HPLC/GC has allowed the collection of several fractions that were analysed by GC and/or GC-MS and, whenever needed, by enantioselective GC.

Conventional on-line multidimensional GC was used to determine ethyl lactate enantiomeric excess [16].

\section{Experimental}

\subsection{Wine samples}

Wine preparation has been carried out at SOGRAPE winery in the Dão region (North Portugal). As soon as alcoholic fermentation was achieved, wines were transferred to 50-1 inox containers. Both containers were kept at $18{ }^{\circ} \mathrm{C}$. These containers followed spontaneous MLF. Samples (one 0.75-1 bottle) were taken each weekday (during November and December 1999) until complete MLF (followed by paper chromatography at the winery) and stored at $4{ }^{\circ} \mathrm{C}$. After MLF completion, the remaining wines were transferred to bottles and kept at $4{ }^{\circ} \mathrm{C}$ until analysis. Two wines were monitored: 0107 and 0105 .

\subsection{Sample preparation}

Organic acids were extracted by SPE using a $\mathrm{LC}_{18}$ SPE cartridge (Supelco, Bellafonte). The eluates were analysed by HPLC/UV on a Waters instrument model 600E (Waters Corporation, USA) equipped with a Waters 2487 Dual $\lambda$ detector and a Rheodyne injector with a $20-\mu l$ loop. Detection was achieved at $210 \mathrm{~nm}$ on an Aminex HPX-87H column $(300 \times 7.8$ $\mathrm{mm})$ from Bio-Rad. Temperature was kept at $30{ }^{\circ} \mathrm{C}$ and flow-rate was $0.6 \mathrm{ml} \mathrm{min}{ }^{-1}$. Eluent was $\mathrm{H}_{2} \mathrm{SO}_{4}$ $4 \mathrm{~m} M$. Quantification was achieved by a calibration curve obtained for the concentration range of $6.25 \times$ $10^{-4}-1 \times 10^{-2} \mathrm{~mol} 1^{-1}$. Correlation coefficients of 0.9997 and 0.9999 were obtained for the calibration curves of malic and lactic acids, respectively.

Butane-2,3-dione quantification was achieved by SIM-GC-MS analysis of a butane-2,4-dionediacetyl derivative 6,7-dichloro-2,3-dimethylquinoxaline (DCDMQ) according to the method already described by Martineau et al. [17]. The derivatives were analysed by GC-MS using a MD 800 from Fisons. GC separation was achieved using a DB-Wax (J\&W Scientific, Folsom, USA) capillary column $30 \mathrm{~m} \times 0.25 \mathrm{~mm}$ I.D. using helium as the carrier gas at a pressure of $100 \mathrm{kPa}$. Initial oven temperature $80^{\circ} \mathrm{C}$ for $3 \mathrm{~min}$; temperature incremental rate: $20^{\circ} \mathrm{C}$ $\mathrm{min}^{-1}$ up to $200^{\circ} \mathrm{C}$ followed by a second ramp of $10{ }^{\circ} \mathrm{C} \mathrm{min}{ }^{-1}$ up to $260{ }^{\circ} \mathrm{C}$. Injector temperature: $200{ }^{\circ} \mathrm{C}$. Interface temperature: $250^{\circ} \mathrm{C}$ and ion source $200{ }^{\circ} \mathrm{C}$. Detection was achieved by monitoring the fragment ions $\mathrm{m} / \mathrm{z} 74,109,144,185$ and 226 for DCDMQ derivative whereas $\mathrm{m} / \mathrm{z} 57,85,113,183$ and 268 were used for nonadecane (internal standard). Quantification was accomplished by the area ratio versus concentration ratio using the internal standard method. According to others [17] calibration curves for DCDMQ were linear within the concentrations ratios studied. Within run precision was estimated by injecting the same sample seven times. A relative standard deviation of $0.172 \%$ was determined.

\subsection{Ethyl lactate analysis}

For ethyl lactate analysis, $25 \mathrm{ml}$ of wine was dealcoholized by vacuum distillation until $75 \%$ of the initial volume. To this solution $2.5 \mathrm{ml}$ of a solution ( $1 \%$ in water) of the internal standard (methyl lactate) was added and the volume $(25 \mathrm{ml})$ made up with deionised water. From this solution, $10 \mathrm{ml}$ was extracted with $3 \times 10 \mathrm{ml}$ dichloromethane. 
The extracts were combined and evaporated under nitrogen until a final volume of about $2 \mathrm{ml}$. From this solution, $1 \mu \mathrm{l}$ was used for GC analysis.

GC analysis was carried out using a $30 \mathrm{~m} \times 0.25$ mm I.D. DB-Wax column (J\&W Scientific), a GOWMAC series 600 GC (GOW-MAC Instrument Co., Shannon, Ireland), and split injection. Oven temperature was kept at $80^{\circ} \mathrm{C}$. Detector and injector temperatures were 280 and $250{ }^{\circ} \mathrm{C}$, respectively.

Ethyl lactate $98 \%$ and methyl lactate $98 \%$ from Aldrich were used to prepare the calibration curve. Quantification of ethyl lactate was achieved by the internal standard method. Calibration curves were obtained for a concentration range of $9.8-2507 \mathrm{mg}$ $1^{-1}$ of ethyl lactate using methyl lactate as internal standard in a concentration of $312.4 \mathrm{mg} \mathrm{l}^{-1}$ and dichloromethane as the solvent. The calibration curve is linear with $R^{2}=0.9996$.

\subsection{Multidimensional analysis}

For enantioselective GC, a $30 \mathrm{~m} \times 0.25 \mathrm{~mm}$ I.D. tailor-made fused-silica capillary column coated with $0.25 \mu \mathrm{m}$ film thickness of $15 \%$ heptakis (2,3-di-O methyl-6-O-tert.-butyldimethylsilyl)- $\beta$-cyclodextrin in SE 52 (DiMe) was used. GC conditions were: temperature $65^{\circ} \mathrm{C}$ for $5 \mathrm{~min}$ and then linearly heated at a rate of $2{ }^{\circ} \mathrm{C} \mathrm{min}{ }^{-1}$ to $85^{\circ} \mathrm{C}$ and then $6{ }^{\circ} \mathrm{C} \min ^{-1}$ up to $220{ }^{\circ} \mathrm{C}$ with a holding time of $15 \mathrm{~min}$. Carrier gas velocity was adjusted to a hold up time of $60 \mathrm{~s}$ for methane at $100{ }^{\circ} \mathrm{C}$. Enantio-multidimensional GC-MS (e-MDGC)-MS, was carried out with a Siemens SiChromat 2.8 double oven gas chromatograph and a GCQ ion trap detector (Finnigan Mat), connected to the main column by the ITD transfer line with an open split interface. The first oven held a pre-column $(30 \mathrm{~m} \times 0.25 \mathrm{~mm}$ I.D. fused-silica capillary coated with SE 52) and was equipped with a flame ionisation detector. Carrier gas helium 2.20 bar; split/splitless injector $250{ }^{\circ} \mathrm{C}$; detector $250{ }^{\circ} \mathrm{C}$; Oven temperature $60^{\circ} \mathrm{C}$ linearly increases at a rate of $5{ }^{\circ} \mathrm{C} \min ^{-1}$ to $250{ }^{\circ} \mathrm{C}$. The second oven was equipped with a $30 \mathrm{~m} \times 0.25 \mathrm{~mm}$ I.D. fused-silica capillary, BGB 176 (BGB Analytical Vertrieb, Schloßboeckelheim, Germany) (DiMe $\beta-C D)$, Oven temperature was $45^{\circ} \mathrm{C}$ for 5 min then $5^{\circ} \mathrm{C} \mathrm{min}{ }^{-1}$ up to $220^{\circ} \mathrm{C}$. ITD transfer line $250{ }^{\circ} \mathrm{C}$, helium sweeping flow: $1 \mathrm{ml} \mathrm{min}{ }^{-1}$ ion trap source $170{ }^{\circ} \mathrm{C}$; EI $70 \mathrm{eV}$.
Pre and main column were connected via a liveswitching coupling piece (live $\mathrm{T}$ piece). Retention time on the pre-column was $6.6 \mathrm{~min}$ for ethyl lactate. Cut time interval was 6.3-6.9 min for ethyl lactate. Reproducibility was evaluated by injecting the same sample five times. RSD \% was 0.75 for the $(R)$-ethyl lactate and 1.58 for the $(S)$-ethyl lactate.

\subsection{Aroma compound analysis}

Aroma compounds were extracted as previously described [18]; $50 \mathrm{ml}$ of wine were used to which octan-2-ol was added as internal standard at a concentration of $5 \mathrm{mg} \mathrm{l}^{-1}$. The wine was extracted three times using $15+5+5 \mathrm{ml}$ of dichloromethane. After extraction, the organic layers were collected in the same flask and dried over anhydrous sodium sulphate (E. Merck). The extracts were concentrated by rotary evaporator and gentle nitrogen stream to a final volume of about $100 \mu \mathrm{l}$ (for direct GC injection) and to $500 \mu \mathrm{l}$ when previous HPLC prefractionation was carried out.

\subsection{Pre-fractionation by $H P L C$}

Four hundred microliters of extract was fractionated in two successive injections on an HPLC Waters model 600E equipped with a UV detector Waters 2487 using a $200-\mu l$ sample loop. Fractions were collected every $2 \mathrm{~min}$. The final total volume of sample was $8 \mathrm{ml}$. The column used was a semipreparative Interchim column (Interchim, Montluçon, France); $250 \times 10 \mathrm{~mm}$ packed with Lichrosorb diol (particle size $5 \mu \mathrm{m}$ ). The initial eluent was pentane/diethyl ether $(9: 1 \mathrm{v} / \mathrm{v})$ increased to $100 \%$ ether in $30 \mathrm{~min}$. The column was then equilibrated with methanol for $20 \mathrm{~min}$, reequilibrated with ether for $5 \mathrm{~min}$ and again pentane/ether $(9+1$ $\mathrm{v} / \mathrm{v})$ for an extra $5 \mathrm{~min}$. All solvents were HPLC grade. The flow-rate was $2 \mathrm{ml} \mathrm{min}{ }^{-1}$. Fractions were concentrated to about $100 \mu \mathrm{l}$ before GC analysis.

\subsection{Gas chromatographic and gas \\ chromatography-mass spectrometric analysis}

Gas chromatographic analysis was carried out with a GOW-MAC series 600 gas chromatograph (GOWMAC Instrument Co.) equipped with a flame ionisa- 
tion detector (FID), linked to a PC with Chromeleon (Dionex) software. GC separation was carried out on a DB-Wax $60 \mathrm{~m} \times 0.25 \mathrm{~mm}$ I.D., film thickness 0.25 $\mu \mathrm{m}$ (J\&W Scientific). Operating conditions were as follows: injector and detector temperature $250{ }^{\circ} \mathrm{C}$; carrier gas, $\mathrm{H}_{2} 1 \mathrm{ml} \min ^{-1}$; oven temperature program, $3 \mathrm{~min}$ at $50{ }^{\circ} \mathrm{C}$ then $2{ }^{\circ} \mathrm{C} \min ^{-1}$ up to $210{ }^{\circ} \mathrm{C}$ and held until the end. Injection volume was between 0.5 and $1.0 \mu$ l. Injection mode: splitless for 1 min.

For enantioselective chromatography, a $30 \mathrm{~m} \times$ $0.25 \mathrm{~mm}$ I.D. tailor-made fused-silica capillary column coated with $0.25 \mu \mathrm{m}$ film thickness of $15 \%$ heptakis (2,3-di- $O$-methyl-6-O-tert.-butyldimethylsilyl)- $\beta$-cyclodextrin in SE 52 (DiMe) was used. GC operating conditions were the same, except for a higher GC time. The oven was programmed from 210 to 220 at $10{ }^{\circ} \mathrm{C}$ and held until the end. Chromatography was carried out using the same GC apparatus.

GC-MS analysis was carried out using a GCTrace Thermo Quest Instrument coupled to a MSTrace Finnigan-Mat (EI, $70 \mathrm{eV}$ ) and the same DBWax column. Analytical conditions: interface temperature $220{ }^{\circ} \mathrm{C}$; ion source temperature $200{ }^{\circ} \mathrm{C}$. GC operating conditions were identical to those described above, using helium as the carrier gas. The mass spectrometer was scanned either over the range $m / z \quad 40-300$ or by time-scheduled selected ion monitoring (SIM). SIM was used to achieve better identification and $R / S$ ratio determinations.

\subsection{Standards used for stereoisomer identification}

$(R, R)$-Butane-2,3-diol; (S,S)-butane-2,3-diol and meso-butane-2,3-diol used for stereoisomer identification were purchased from Sigma with 97, 99 and $97 \%$ enantiomeric purity, respectively; ethyl $(R)-(-)$ hydroxybutyrate was purchased from Aldrich with 98\% enantiomeric purity while the $S$ compound was also from Aldrich but with $99 \%$ enantiomeric purity. Pentane-2,4-diol was also from Aldrich and both stereoisomers had an enantiomeric purity of $99 \%$. For 2-methylbutan-1-ol, only the $S$ enantiomer was tested (from Aldrich) with an enantiomeric purity of 99\%. (S)-Ethyl lactate was from Aldrich with an enantiomeric purity of $98 \%$. All optical purities were confirmed by enantioselective GC analysis.

\subsection{Panel tests}

To verify aromatic impact, the three stereoisomers of butane-2,3-diol and pentane-2,4-diol were submitted to an untrained sensory evaluation panel. Different aqueous stock solutions were prepared as follows: meso-butane-2,3-diol $0.006 \mu \mathrm{ml}^{-1},(S, S)$ butane-2,3-diol and $(R, R)$-butane-2,3-diol $0.01 \mu l$ $\mathrm{ml}^{-1}$, and pentane-2,4-diol $0.05 \mu \mathrm{l} \mathrm{ml}^{-1}$. Several successive dilutions of these stock solutions were used.

To each panelist, a glass with between 10 and $20 \mathrm{ml}$ of each dilution was given. Panelists were asked to assign a description and note the limit above which aroma could be detected.

\section{Results and discussion}

The so-called "key turn points" (start, middle and end) of MLF were determined by controlling the evolution of the ratio lactic/malic (L/M) acids, starting just after alcoholic fermentation. This ratio increases with time. After the 17th day, the concentration of malic acid could not be detected for wine 0107 , whilst wine 0105 shows a ratio $(\mathrm{L} / \mathrm{M})$ of 95 after 21 days. Butane-2,3-dione (a key compound of MLF) $[17,19,20]$ reaches a maximum (around days 12-14), decreasing at the end of MLF when the $\mathrm{L} / \mathrm{M}$ stabilizes. These results are in good agreement with the evolution followed by the L/M ratio. These two sets of results were used to determine the evolution of MLF. Ethyl lactate increases during MLF from 0.06 to $14.20 \mathrm{mg}^{-1}$ for wine 0105 and 0.15 to $47.78 \mathrm{mg} \mathrm{l}^{-1}$ for wine 0107 . These results are in agreement with others that concomitantly refer to unpleasant notes when its intensity is too high [21]. The enantiomeric ratio of the produced ethyl lactate was monitored at the start middle and end of MLF, using on-line multidimensional GC (Fig. 1). In fact at the beginning of MLF, while there is a high malic acid concentration, one observes a ratio $R / S$ of 62:38 for the 0107 wine and 78:22 for 0105 . However, in both wines, this ratio decreased during MLF reaching the ratios of 53:47 and 57:53 for the respective wines at the end of MLF. Semi-quantitative data has shown that whilst the $R$ enantiomer was reduced by $50-68 \%$ (depending on the wine studied) 


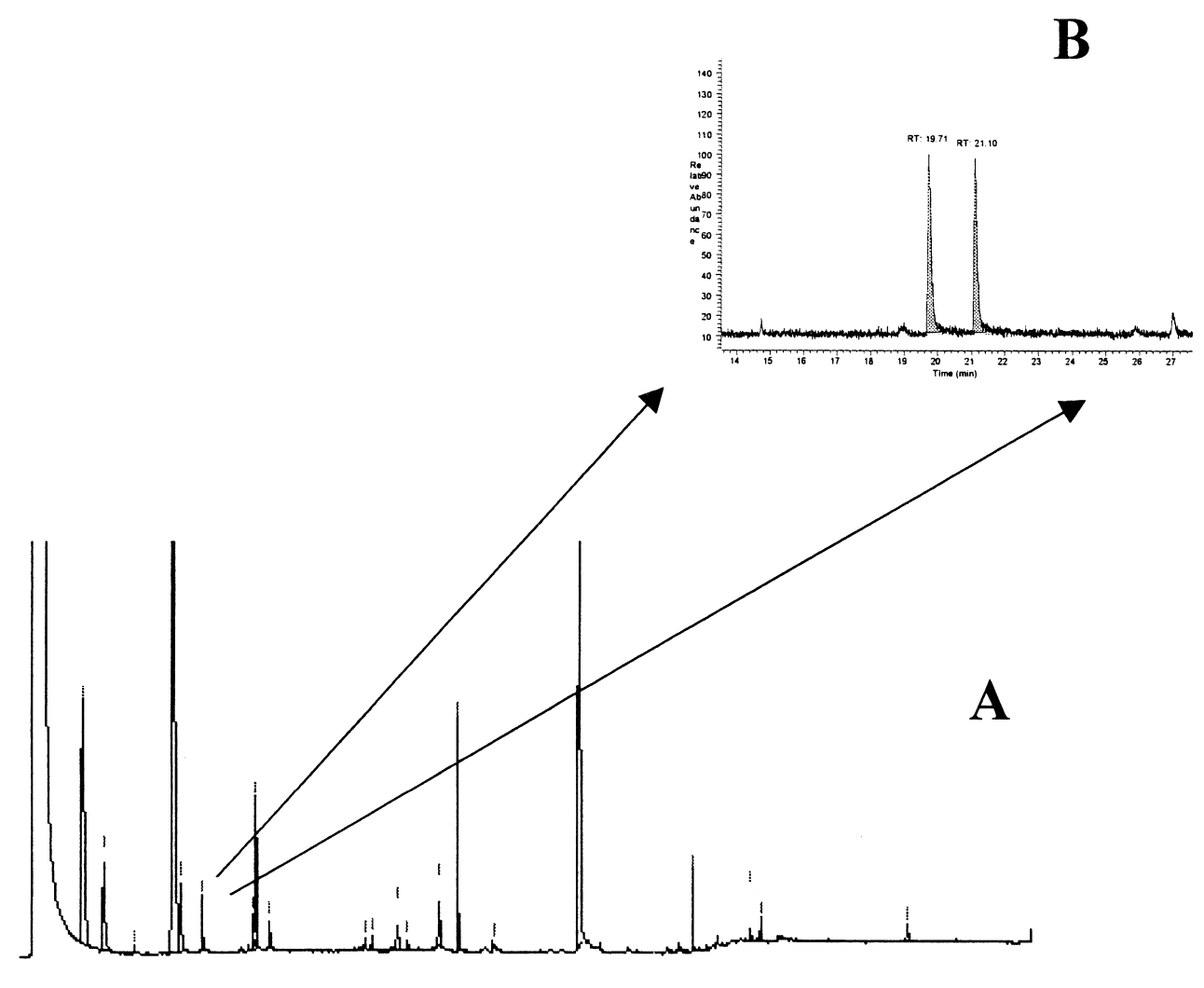

0

90 Minutes

Fig. 1. Enantio-MDGC-MS (A) of a wine using a $30 \mathrm{~m} \times 0.25 \mathrm{~mm}$ I.D. fused-silica capillary coated with SE-52 as pre-column and a 30 $\mathrm{m} \times 0.25 \mathrm{~mm}$ I.D. fused-silica capillary, BGB 176 (BGB Analytic Vertrieb, Schloßböchelheim, Germany) (DiMe $\beta$-CD) as main column. Pre and main column were connected to a live-switching coupling piece (live T-piece). The elution orders of the substances studied were assigned using reference materials of definite chirality. Retention time on the pre column was 6.6 min for ethyl lactate. Cut time interval was: $6.3-6.9 \mathrm{~min}$ for ethyl lactate (B).

during MLF the $S$ enantiomer was raised $85-78 \%$. The high percentage of $(S)$-ethyl lactate found in these samples agrees with the induction of MLF by spontaneous infection [16].

To study the evolution of volatile compounds during MLF, dichloromethane extracts of wine samples were analyzed at previously determined "key turn points". The GC and GC-MS-TIC chromatograms obtained are rather complex and do not show relevant qualitative differences. Volatile compounds were tentatively identified from their mass spectra by comparison with library data (Wiley Spectral library). Table 1 shows the identified compounds in the three stages of MLF studied, an asterisk denotes the chiral compounds. Semi-quantitative results $(\mu \mathrm{g}$ $\mathrm{ml}^{-1}$ of wine) were calculated from peak area of components versus area of internal standard [22]; no response factors were used [1,14,22]. We could observe from data on Table 1 that some of the compounds rose and others decreased during MLF. Most, however, did not suffer any change. Belonging to the first group are: 3-hydroxybutan-2-one, ethyl lactate, 3-methylbutan-1-ol, diethyl succinate, 2phenylethanol, 2-methylpropan-1-ol, both peaks of butane-2,3-diol (meso, and the enantiomeric pair $R, R$ and $S, S$ ), and the acetic and hexanoic acids. Between the groups of compounds that decreased during MLF are the acids and some alcohols; 3- and 2methylbutan-1-ol, propane-2,3-diol, 2-ethylhexan-1ol and benzyl alcohol. Others did not show any 
Table 1

Semi-quantitative analysis of compounds identified in wine 0107 (total sample) at start, middle and end of MLF

\begin{tabular}{|c|c|c|c|c|}
\hline Peak no. & Compound name & Begin FML & Middle FML & End FML \\
\hline 1 & Isobutyl acetate & 0.0925 & 0.1762 & 0.0358 \\
\hline 2 & Propan-1-ol & - & - & 0.1736 \\
\hline 3 & 2-Methylpropan-1-ol & 1.0598 & 1.0072 & 3.1346 \\
\hline 4 & Isopentyl acetate & 0.6170 & 0.9458 & 0.0539 \\
\hline 5 & Butan-1-ol & 0.0525 & 0.0579 & 0.0528 \\
\hline 6 & $3+2-$ Methylbutan-1-ol ${ }^{\mathrm{b}, \mathrm{d}}$ & 4.7099 & 4.4395 & 2.2246 \\
\hline 7 & Ethyl hexanoate & 0.0683 & 0.0863 & 0.0333 \\
\hline 8 & 3-Hydroxybutan-2-one $e^{b, d}$ & 0.6879 & 1.4029 & 1.9251 \\
\hline 9 & Ethyl lactate ${ }^{\mathrm{b}, \mathrm{d}}$ & 0.7390 & 1.3524 & 2.3211 \\
\hline 10 & Hexan-1-ol & 0.2867 & 0.2546 & 0.2015 \\
\hline 11 & 3-Ethoxypropan-1-ol & 0.0438 & 0.0342 & 0.0222 \\
\hline 12 & Hex-3-en-1-ol & 0.0081 & 0.0101 & 0.0096 \\
\hline 13 & Octan-2-ol ${ }^{\mathrm{a}}$ & 1.000 & 1.000 & 1.000 \\
\hline 14 & Ethyl octanoate & $0.0164^{\mathrm{c}}$ & $0.0200^{\mathrm{c}}$ & $0.0448^{\mathrm{c}}$ \\
\hline 15 & Acetic acid & $0.2827^{\mathrm{c}}$ & $0.4004^{\mathrm{c}}$ & $0.8113^{\mathrm{c}}$ \\
\hline 16 & Furfural & - & - & 0.0040 \\
\hline 17 & Isopentil hexanoate & 0.0311 & 0.0242 & - \\
\hline 18 & 2-Ethylhexan-1-ol ${ }^{\mathrm{b}, \mathrm{d}}$ & 0.0832 & 0.0688 & 0.0061 \\
\hline 19 & Ethyl 3-hydroxybutanoate ${ }^{\mathrm{b}, \mathrm{d}}$ & 0.0650 & 0.0730 & 0.0321 \\
\hline 20 & Benzaldehyde & 0.0156 & 0.0128 & - \\
\hline 21 & $(R, R)+(S, S)$ Butane-2,3-diol ${ }^{\mathrm{b}, \mathrm{d}}$ & 1.4645 & 1.2329 & 2.9051 \\
\hline 22 & Octan-1-ol & 0.0067 & 0.0081 & 0.0050 \\
\hline 23 & 2-Methylpropanoic acid & 0,1902 & 0.1888 & 0.1151 \\
\hline 24 & meso Butane-2,3-diol ${ }^{\mathrm{b}, \mathrm{d}}$ & 0.3498 & 0.2347 & 1.2214 \\
\hline 25 & Propane-1,2-diol ${ }^{\mathrm{d}}$ & 0.0966 & 0.0732 & 0.0092 \\
\hline 26 & Butanoic acid & 0.1011 & 0.0913 & 0.0524 \\
\hline 27 & $N$-Ethylacetamide & 0.0571 & 0.0287 & 0.0367 \\
\hline 28 & Butane-4-lactone ${ }^{\mathrm{b}}$ & 0.8326 & 0.7557 & 0.8477 \\
\hline 29 & Ethyl decanoate & 0.0138 & 0.0084 & - \\
\hline 30 & 3-Methylbutanoic acid & 0.2301 & 0.2292 & 0.1010 \\
\hline 31 & Diethyl succinate & 0.5974 & 1.2272 & 1.2225 \\
\hline 32 & 3-(Methylthio) propan-1-ol & 0.1309 & 0.1368 & 0.0390 \\
\hline 33 & Ethyl 4-hydroxybutanoate & 0.2236 & 0.4531 & 0.3362 \\
\hline 34 & 2-Phenylethyl acetate & 0.1128 & 0.1454 & 0.0139 \\
\hline 35 & Hexanoic acid & $0.0196^{\mathrm{c}}$ & $0.0202^{c}$ & $0.2159^{c}$ \\
\hline 36 & $N$-Isopentylacetamide & 1.9076 & 1.5734 & 1.7834 \\
\hline 37 & Benzyl alcohol & 0.0270 & 0.0091 & - \\
\hline 38 & Phenylethyl alcohol & 2.4768 & 2.0476 & 3.6624 \\
\hline 39 & Diethyl hydroxybutanedioate $^{\mathrm{d}}$ & $0.0869^{\mathrm{c}}$ & $0.0521^{\mathrm{c}}$ & $0.0229^{c}$ \\
\hline 40 & Octanoic acid & 0.4397 & 0.4136 & 0.3104 \\
\hline 41 & 4-Ethenyl-2-methoxyphenol & 0.0832 & 0.0688 & 0.0061 \\
\hline 42 & Decanoic acid & 0.0886 & 0.0469 & 0.0403 \\
\hline 43 & Monoethyl succinate & 4.1454 & 5.3307 & 9.4582 \\
\hline 44 & $N$-(2-Phenylethyl) acetamide & 0.2502 & 0.2332 & - \\
\hline
\end{tabular}

${ }^{\mathrm{a}}$ Internal standard.

${ }^{\mathrm{b}}$ Identified with standards.

${ }^{\mathrm{c}}$ Areas calculated by SIM.

${ }^{\mathrm{d}}$ Chiral compounds.

relevant change. In order to simplify and resolve coelution problems, an off-line multidimensional chromatography approach was used where the first separation was achieved by HPLC (first dimension) followed by a second separation by either normal GC-MS or enantio GC-MS. HPLC chromatography 
allowed the fractionation of the extract by compound families, 22 fractions were collected. The analysis of these fractions by GC-MS allowed further identification of an additional 38 compounds (Table 2). This method acknowledged: (a) the identification of a large number of compounds that could not be identified before, probably, because they coeluted with major compounds; (b) the identification of trace compounds; (c) the separation of compounds that normal GC, using Carbowax-coated columns was not able to separate, like 3-methylbutan-1-ol and 2methylbutan-1-ol. During fractionation, the first appeared in fraction 11 whereas the second came in fraction 10. To the aroma of 3-methylbutan-1-ol, oily and whiskey aromas have been assigned [23,24] whilst the 2-methylbutan-1-ol has not been referred as having any aromatic signature.

The chiral compounds identified (Table 1) deserved special attention. The biosynthesis of these compounds is often enantioselective [6], and the quantification of the enantiomeric ratio can be used to improve the knowledge of the aroma and quality of wines. In addition, determination of enantiomeric excess (ee) can be used to detect aromatisation with

Table 2

Compounds identified after fractionation by HPLC

\begin{tabular}{|c|c|}
\hline Alcohols & Acids \\
\hline Glycerol & Hexadecanoic acid \\
\hline Pentan-1-ol & Esters \\
\hline Pentan-2-ol ${ }^{\mathrm{a}}$ & Ethyl acetate \\
\hline 2-Methylbutan-1-ol ${ }^{\mathrm{a}}$ & Ethyl pyruvate \\
\hline 3-Methylbutan-1-ol ${ }^{\mathrm{a}}$ & Propane-1,3-diol, diacetate \\
\hline cis Hex-3-en-1-ol & Diethyl malonate \\
\hline trans Hex-3-en-1-ol & Hexyl acetate \\
\hline 3-Methylpentan-1-ol & Butane-1,4-diol, diacetate \\
\hline 4-Methylpentan-1-ol & Octyl acetate \\
\hline Heptan-1-ol & Lactones \\
\hline 2,6-Dimethoxyphenol & Pentane-4-lactone \\
\hline Nonan-1-ol & Aldehydes \\
\hline Nonan-2-ol & Phenylethanal \\
\hline 3-(2-Hydroxyethyl)-indol & Nonanal \\
\hline Decan-1-ol & Terpenes \\
\hline Pentane-2,4-diol & Linalool $^{\mathrm{a}}$ \\
\hline Acids & Nerol $^{\mathrm{a}}$ \\
\hline Propanoic acid & Geraniol \\
\hline 2-Methylbutanoic acid & Citronelol \\
\hline Pentanoic acid & Others \\
\hline trans Hex-2-enoic acid & Dimethyl sulfone \\
\hline Heptanoic acid & Furfurol \\
\hline
\end{tabular}

${ }^{\mathrm{a}}$ Identification by standard coelution. synthetic chiral aroma substances. Among the chiral compounds identified: butane-2,3-diol; ethyl 3-hydroxy butyrate; 3-hydroxybutan-2-one; pentane-2,4diol and 2-methylbutan-1-ol were submitted to enantioselective GC. The identification of the different stereoisomers was obtained by either coinjection with pure enantiomeric standards or biosynthetic deduction as proposed further for 3-hydroxybutan-2one. Quantification to assess enantiomeric ratios during MLF was achieved by means of enantioselective GC-MS-SIM using the following characteristic $\mathrm{m} / \mathrm{z}$ ions: 76, 117,88 and 71 , respectively for butane-2,3-diol, ethyl 3-hydroxybutyrate, 3-hydroxybutan-2-one and pentane-2,4-diol. Quantification was not necessary for 2-methylbutan-1-ol because only the $S$ enantiomer was found during MLF. Fig. 2 shows the enantiomeric ratio of these compounds at the three key points of MLF. For ethyl 3-hydroxybutyrate, we could not observe quantitative enantiomeric changes during MLF, the aroma related to this compound is fresh, fruity and grape-like [23,24]; 3-hydroxybutan-2-one and butane-2,3-diol on the other hand showed a different behaviour. To assess the order of elution for the three stereoisomers of butane-2,3-diol, each enantiomeric standard were separately injected. The order of elution was as follows, $R, R$ followed by the $S, S$ and the meso compound come at the end. For 3-hydroxybutan-2one, no enantiomeric forms were available, however, following Prelog's rule, the yeast-reduction of butane-2,3-dione produced (S)-3-hydroxybutan-2one, further reduction yields the corresponding 2,3butanediol predominantly in the anti-configuration, which is in accordance with our results, where the meso form rose in the early stage of MLF. It seems natural to conclude that the $(S)$-3-hydroxybutan-2one is the enantiomer that concomitantly decreases. This result is in accordance with similar orders of elution found by others [25] for compounds having similar structures. Special attention has been addressed to pentane-2,4-diol, which was only identified at the end of MLF (fraction 18). This compound has never been noted as part of wine aroma nor, to the best of our knowledge, as part of the aroma of fruit. Its identification was carried out by GC-MS spectral analysis, retention time, and injection of a standard under similar conditions. Elution order of the three stereoisomers was determined 
Butane-2,3-diol

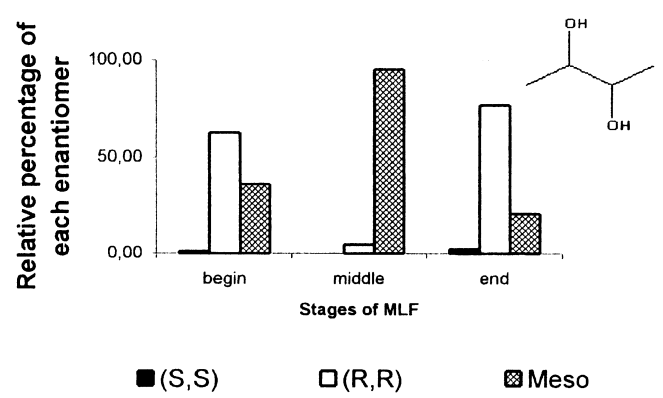

Ethyl 3-hydroxybutyrate

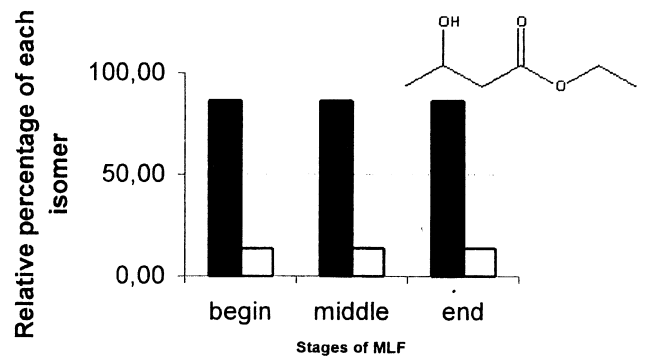

(S) Ethyl-3-hydroxybutyrate $\square(R)$ Ethyl-3-hydroxybutyrate

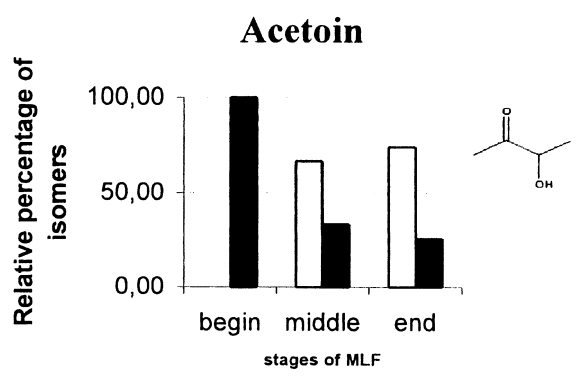

Denantiomer 1

Denantiomer 2

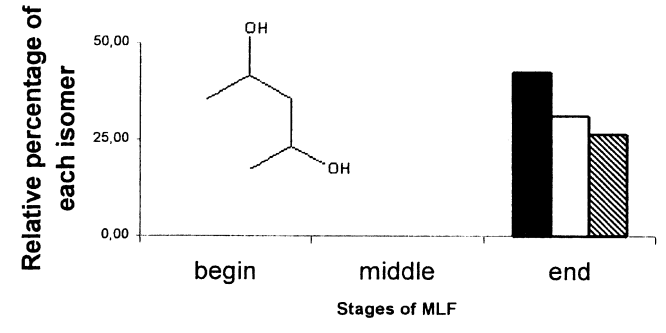

$(S, S) \quad \square(R, R) \quad$ meso

Fig. 2. Ratio of selected isomers found along the three stages of MLF.

by e-GC-MS. Literature [26] notes that $(R, R)$-pentane-2,4-diol can be obtained by enantioselective reduction of acetylacetone (pentane-2,4-dione) from the resting cells of methanol yeast, Candida boidini, a wild yeast that can also be present during wine processing. Although contamination cannot be completely excluded, the fact that the compound was present in two different wines virtually excluded this assumption. Pentane-2,4-dione and 4-hydroxypentan2-one were also detected in the three stages of MLF studied. These compounds are not listed in Tables 1 and 2 since these just refer to compounds previously cited in the literature.

To demonstrate the impact of enantioseparation, water solutions of the three stereoisomers of butane2,3-diol and pentane-2,4-diol were sniffed by an untrained panel. Descriptors used were not suggested or confirmed by positive assignment. Results clearly show that each stereoisomer of butane-2,3-diol has a different aromatic note. Since pentane-2,4-diol has never been noted as part of wine aroma, its odorant impact was also tested; two-thirds of the panelists attributed an aroma descriptor and still recognized the aroma at a concentration of $6 \mu \mathrm{ll}^{-1}$.

\section{Acknowledgements}

We wish to thank Professor A. Mosandl, Johann Wolfgang Goethe University, for the use of the MDGC-MS apparatus and Fundação para a Ciência e Tecnologia for financial support as POCTI/AGR/ $11116 / 98$.

\section{References}

[1] W. Bertsch, J. High Resolut. Chromatogr. 12 (1999) 647. [2] D. Barron, Z. Lebensm.-Unters.-Forsch. 193 (1991) 454. 
[3] V. Ferreira, R. López, A. Escudero, J.F. Cacho, J. Chromatogr. A 806 (1998) 349.

[4] V. Ferreira, M. Sharman, J.F. Cacho, J. Dennis, J. Chromatogr. A 731 (1996) 247.

[5] A. Rapp, Nahrung 42 (1998) 351.

[6] H.D. Belitz, W. Gorsch, Food Chemistry, Springer, Heidelberg, 1999, p. 329.

[7] D.R. Davis, D. Wibowo, R. Eschenbruch, T.H. Lee, Am. J. Enol. Vitic. 36 (1985) 290.

[8] T. Henick-Kling, T.E. Acree, S.A. Krieger, M. Laurent, W.D. Edinger, Wine East, 3rd Biotechnology Dossier, Vignevini, 1994, pp. 120-138.

[9] M.H. Laurent, T. Henick-Kling, T.E. Acree, Vitic. Enol. Sci. 49 (1994) 3.

[10] F. Tateo, M. Bononi, F. Trambaiolo, S. Cunial, in: P. Sandra (Ed.), Proceedings of the 18th International Symposium on Capillary Chromatography, Hüethig Verlag, Heidelberg, 1995, p. 1122.

[11] G. de Revel, N. Martin, L. Pripis-Nicolau, A. LonvaudFunel, A. Bertrand, J. Agric. Food Chem. 47 (1999) 4003.

[12] M.S.F. Ross, J. Chromatogr. 118 (1976) 273.

[13] M.S.F. Ross, J. Chromatogr. 160 (1978) 199.

[14] J.E. Newbery, M.P. Lopez de Haddad, J. Chromatogr. 260 (1983) 173.
[15] H. Komae, N. Hayashi, J. Chromatogr. 114 (1975) 258.

[16] A. Kaunzinger, M. Wust, H. Grobmiller, S. Burow, U. Hemmrich, A. Dietrich, T. Beck, U. Hener, A. Mosandl, A. Rapp, Z. Lebensm.-Unters.-Forsch. 203 (1996) 499.

[17] B. Martineau, T. Henick-Kling, T. Acree, Am. J. Enol. Vitic. 46 (1995) 385.

[18] C. Cocito, G. Gaetano, C. Delfini, Food Chem. 52 (1995) 311.

[19] B. Martineau, T. Acree, T. Henick-Kling, Biotechnol. Tech. 8 (1994) 7.

[20] Y. Hayasaka, E. Bartowsky, J. Agric. Food Chem. 47 (1999) 612.

[21] T. Henick-Kling, Malolactic fermentation, in: G.H. Fleet (Ed.), Wine Microbiology and Biotechnology, Harwood Academic, Chur, 1993, p. 289.

[22] E. Valero, M.J. Villasenor, J. Sanz, I. Martinez Castro, Chromatographia 52 (2000) 340.

[23] Flavors and Fragrances, 2001, Aldrich, International Edition.

[24] T. Acree, H. Arn, in http://www.nysaes.cornell.edu/flavornet/index.html

[25] A. Dietrich, Ph.D. Thesis, Johann Wolfgang Goethe University, Frankfurt am Main, 1996.

[26] S. Matsumura, Y. Kawai, Y. Takahashi, K. Toshima, Biotechnol. Lett. 16 (1994) 485. 